\title{
Filatelia como mecanismo de divulgação e de ensino para as Engenharias no Brasil
}

Júlio César Penereiro

Denise Helena Lombardo Ferreira

\begin{abstract}
Resumo
Este artigo propõe que é possível divulgar e ensinar aspectos das engenharias por meio das imagens presentes nos selos postais comemorativos. 0 selo postal pode ser um poderoso meio de divulgação científica para sensibilizar as sociedades, de um modo geral, sobre a importância das pesquisas científicas e o que foi realizado no campo das engenharias. Muitas deficiências nas informações e no ensino das engenharias poderiam ser minimizadas com a ajuda de veículos de comunicação menos usuais, como os selos postais, cujo alcance estende-se além das fronteiras meramente comerciais. No presente trabalho faz-se um retrospecto do aparecimento e uso dos selos postais no Brasil, seu papel cultural e o desenvolvimento das emissões abordando temas da engenharia. Analisam-se todos os selos brasileiros emitidos entre 1843 a 2010, classificando aqueles com conotações nas engenharias. Apresenta-se também uma proposta para maior divulgação do patrimônio da engenharia do Brasil, por meio desse veículo de comunicação.
\end{abstract}

Palavras-chave: ensino e aprendizagem, filatelia brasileira, ensino de engenharia, selos postais.

\footnotetext{
Abstract

Philately as a mechanism of disseminating and teaching to the Engineering in Brazil

This paper proposes that it is possible to communicate and teach aspects of engineering courses through commemorative postal stamp images. The postal stamp may well be another powerful way of communicating science, to persuade societies, in general, about the relevance of scientific research and what was made in the field of engineering. Much of the lack of information and teaching in engineering could be reduced by the use of a more unusual way of communication as postage stamps, whose range goes far beyond the trade boundaries. In this paper we present a retrospect of the birth and usage of postage stamps over Brazil, it's cultural face and the evolution of issues featuring subjects within the field of engineering. We have analyzed all Brazilian stamps issued from 1843 to
} 
2010, classifying those with connotations in engineering. We also present a proposal to increase the divulgation of the engineering heritage of Brazil, by mean of this simple way.

Keywords: teaching and learning, Brazilian philately, engineering teaching, postal stamps.

\section{Introdução}

A história dos selos postais inicia-se a cerca de 170 anos, pois até meados do século XIX os serviços prestados pelos correios, como regra geral, eram pagos pelo destinatário por ocasião do recebimento da correspondência. Esse procedimento gerava problemas e ônus ao erário público, por conta das correspondências devolvidas e endereços não encontrados. Com a intenção de evitar esse problema, na Inglaterra, o administrador geral dos correios, Sir Rowland Hill, entendeu que esses serviços deveriam ser pagos antecipadamente e assim idealizou um pequeno retângulo de papel com um valor predeterminado estampado, que deveria ser colado na missiva ou carta, indicando que ela já estava devidamente franqueada. Dessa forma nasceu o primeiro selo do mundo, o Penny Black (com valor facial de "one penny" mostrando um retrato de perfil do rosto da rainha Vitoria), entrando em circulação a partir de 1840.

O Brasil foi o segundo país do mundo a adotar o selo postal, por ocasião de um decreto assinado pelo Imperador D. Pedro II em 1841. Porém, a famosa série denominada "Olhos de Boi" (com selos de valores correspondentes a 30, 60 e 90 réis) apenas entrou em circulação a partir de 1843, tornando-se o terceiro país a, efetivamente, utilizar a revolucionária concepção proposta pelo Sir Hill. Após esta série o país criou em 1844 os denominados selos "Inclinados"; em 1850 os "Verticais", conhecidos como "Olhos de Cabra"; e em 1854 os "Coloridos", referidos como "Olhos de Gato". Apenas em 1866, em decorrência do aumento das tarifas postais e da unificação do porte (sem distinção entre o porte terrestre e o marítimo), é que o selo brasileiro passou a estampar imagens de personalidades, sendo a primeira delas do imperador D. Pedro II (Thiéblot, 1994).

O termo Filatelia (formada pelas palavras gregas: philos = amigo, ou o que ama; telos = tributo, ou imposto) apareceu pela primeira vez em 1864, aplicado ao colecionador de selos, na revista "Le Collectioneur de Timbres-Poste". Logo nas primeiras décadas do século XX, os serviços postais entre os países se ampliaram e se aperfeiçoaram. As correspondências passaram a ser enviadas com maior eficiência por meios terrestres e marítimos. Por volta do início da década de 1920 os correios passaram a se servir dos serviços aéreos, sendo que também nessa época se descobre o valor propagandístico dos selos e, por intermédio desses, os motivos turísticos, comerciais, educacionais e patrióticos assumem posição de destaque no cenário postal. Em 1930 o governo federal criou o Departamento de Correios e Telégrafos, substituído em 1969 pela 
Empresa Brasileira de Correios e Telégrafos (Ect, 2010), então subordinada ao Ministério das Comunicações.

Ao longo do tempo, a ECT tem procurado, por meio das emissões de selos postais, conscientizar a comunidade para a importância de preservar e cultuar o rico patrimônio natural, cultural e arquitetônico do país, apresentando imagens, desenhos, fatos e datas de destaque nos mais diversos campos. Segundo esse ponto de vista, Fonseca (2008) lembra ainda que a filatelia apresenta-se como uma ciência auxiliar para os diversos ramos do conhecimento humano. Isso reforça a ideia que os selos são muito mais do que meros comprovantes de tarifas pagas por serviços postais, eles contém diversas fontes de informações sobre aspectos socioculturais, históricos, científicos e econômicos de uma nação, e assim constituem-se num importante veículo na divulgação da imagem de uma sociedade.

A disseminação dos selos fez com que o seu uso fosse visto como um eficaz meio de comunicação de massa, divulgando e popularizando conhecimentos de diversas áreas (Castro; Diniz; Barros, 2007). Assim, não é uma surpresa saber que existem várias publicações na área, por hora denominada, de "ciência filatélica", estimando-se que haja pelo mundo cerca de 500 obras editadas. Contudo, grande parte dessa vasta literatura serve aos filatelistas, ou seja, colecionadores de selos e suas variedades, que representa uma prática bastante difundida, contando com 50 milhões de adeptos (Carazo, 2001).

Por outro lado, em que pese a importância da Internet nos meios de comunicação, os selos postais ainda representam uma ferramenta da mídia que vem ganhando evidência nas últimas décadas no Brasil e no exterior, porém, até o presente momento, esses materiais têm sido pouco explorados em análises científicas no nosso país.

Considerando que os selos postais se destacam como um valioso instrumento de representação das diversas áreas, inclusive as de engenharias, torna-se oportuno usar esse material no ensino e aprendizagem de disciplinas vinculadas a essa área do ensino superior. Como, em parte, destaca Micotti (1999, p. 156), "uma das principais funções da educação escolar é a de assegurar a propagação do saber", não apenas o saber específico, mas também o saber cultural. Essa perspectiva é reforçada pela Resolução CNE/CES 11, de 09 de abril de 2002 do Ministério da Educação, que estabelece no Art. 3o:

O Curso de Graduação em Engenharia tem como perfil do formando egresso/profissional o engenheiro, com formação generalista, humanista, crítica e reflexiva, capacitado a absorver e desenvolver novas tecnologias, estimulando a sua atuação crítica e criativa na identificação e resolução de problemas, considerando seus aspectos políticos, econômicos, sociais, 
ambientais e culturais, com visão ética e humanistica, em atendimento às demandas da sociedade (BRASIL, 2002, p. 32).

É neste contexto que o presente trabalho se ajusta, isto é, realizar análises por meio de um amplo levantamento dos selos emitidos pela ECT hospedados em catálogos e em diferentes endereços eletrônicos disponíveis na Internet. Optou-se por explorar os diversos segmentos da Engenharia, visto que não existe, até a presente data (janeiro/2011), nenhum trabalho nessa área voltado ao estudo dos selos postais. 0 trabalho também visa elaborar conceitos e modelos que sirvam à representação temática dos documentos filatélicos, visto que no seu pequeno espaço físico há relevantes informações da área de Engenharia. Essas informações podem servir como material didático aos professores que desejam estimular seus alunos a apreciar, analisar e estudar as imagens retratando personalidades da nossa história, edificações realizadas, alertas ambientais, além de estudos e conquistas da ciência. Considera-se que essa atitude é salutar para evitar uma eventual postura passiva, podendo estimular a cultura da leitura e a realização de pesquisas na área do ensino da história da ciência. Além disso, o levantamento realizado permite verificar se a filatelia brasileira está cumprindo seu papel de divulgação e incentivo à preservação das obras e monumentos que marcaram a história cultural e científica do país.

\section{Coleções temáticas}

As coleções temáticas surgiram como uma evolução natural da filatelia e consolidaram-se de forma marcante a partir da metade do século passado. Em princípio, as coleções envolveram o agrupamento de selos isolados de diversos países, retratando um tema ou aspecto específico. Essa modalidade de filatelia acabou revelando uma nova faceta ao selo postal: o seu valor cultural e didático, além de um importante veículo de comunicação dos valores de uma dada sociedade (Castro; Diniz; Barros, 2007). Apesar de diferenças entre os vários tipos de coleções, um único ideal une os filatelistas de todo o mundo: a vontade de conhecer mais sobre um local, objeto, pessoa, país, cultura, etc. É exatamente a busca pelo conhecimento que estimula um filatelista a continuar sua coleção, apesar da diminuição das correspondências via o correio tradicional, em função das operações da mídia eletrônica e digital.

Diversos trabalhos empregando os selos postais têm sido publicados contendo séries magníficas retratando temas relacionados com a medicina (Chudley, 1998a; Chudley, Chodirker, 2003; Chordirker; Chudley, 2004), a cartografia (Castro, Diniz, Barros, 2007), a astronomia (Penereiro, 1997), a entomologia (Costa Neto, 2002; Gómez Y Gómez, Junghans, 2002; Ramírez et al., 2006), a física (Morgan, 2006), a flora brasileira (Welker, 2010) e personalidades importantes do mundo científico, como Carl Linnaeus (Chudley, 2001a), Gregor Mendel (Chudley, 1998b), Charles Darwin (Chudley, 2001b), Albert Einstein (Webb, 2005), Dimitri Ivánovich Mendeléiev (Martínez, Peregin, 2007), entre outros. Entretanto, por intermédio de um amplo levantamento 
bibliográfico realizado, percebeu-se que nenhum trabalho envolvendo a temática Engenharia foi publicado até o momento, empregando os materiais disponíveis da filatelia brasileira. Decerto, este trabalho torna-se pioneiro, não apenas para o público interessado pela filatelia, mas também para aqueles professores que atuam em diferentes áreas das Engenharias e que apreciam a história e as conquistas desse ramo da Ciência. Também é possível, por meio da filatelia, oferecer as pessoas, em particular aos seus estudantes em formação profissional, um estudo mais aprofundado, íntimo, sedutor, instigante, esclarecedor e científico, a respeito de um espaço visual de ordens políticas, culturais e temáticas do Brasil ao longo desses mais de um século e meio de existência dos selos postais.

\section{Metodologia e material empregado}

Como metodologia de coleta e organização dos dados para o trabalho, fez-se uso da análise dos selos postais emitidos pela ECT, durante os anos de 1843 a 2010, por intermédio da coleção particular de um dos autores e do "Catálogo de Selos do Brasil 2010" (Meyer, 2010). Além desses procedimentos, fez-se uso da Internet, por meio de consultas a vários endereços eletrônicos acessando o endereço "Google", visando cobrir eventuais lacunas existentes devido à falta de algum material filatélico. $\mathrm{O}$ uso dessas fontes possibilitou reunir todos os selos emitidos pelo Brasil até a atualidade. Durante as consultas realizadas nesses canais, foram contabilizadas 4255 diferentes estampas postais, divididas, segundo a proposta de Meyer (2010), nas seguintes categorias: selos regulares, filigranados, comemorativos, Hansen, personalizados, promocionais, blocos e selos-etiqueta. Por não ser significativo, diante das análises a que o trabalho se propôs realizar, o levantamento não considerou materiais envolvendo: envelopes de primeiro dia de circulação, marcas postais de isenção de porte, folhinhas filatélicas, bilhetes e cartas-bilhete, cadernetas e cartela de selos.

Diante do levantamento realizado, foi possível identificar os selos referentes aos eixos temáticos das diferentes Engenharias. Por meio de planilhas do Microsoft Excel, esse material foi agrupado e contabilizado por assuntos abordados nas sub-áreas da grande área Engenharias, segundo a divisão proposta por Pedroso e Pilatti (2009). Também foram agrupados aqueles selos conotando as personalidades brasileiras (ou estrangeiras, quando fosse o caso), além das estampas que lembraram e/ou homenagearam as realizações de congressos, simpósios, clubes, escolas, etc, que contribuíram para o desenvolvimento dessa ciência. Para as edições postais contendo blocos comemorativos com mais de um selo, esses foram contados separadamente.

Nas seções seguintes são apresentadas as formas em que os dados foram organizados e as estatísticas contendo todas as informações relevantes. 


\section{Os temas de engenharias: resultados e discussões}

No período em que o levantamento deste trabalho se envolveu (1843-2010), o Brasil emitiu 4255 selos postais. Considerando o elevado número de selos envolvidos, a ampla abrangência e a grande quantidade dos temas existentes, procedeu-se a seleção e o agrupamento do conjunto filatélico por meio de eixos-temáticos. Do total de emissões computadas, $654(15,4 \%)$ são referentes ao "eixo-temático central", denominado por Engenharias. Esse eixo-temático apresentou mais emissões que os motivos em Biologia (501 selos; $11,8 \%$ do total), em Arquitetura (403 selos, 9,5\%), nos Esportes (235 selos; 5,5\%) e os 96 (2,2\%) que se referem ao Natal. Esse último caso causou surpresa devido ao número reduzido de selos, tendo em vista que o país possui características religiosas marcantes. A Figura 1 mostra um histograma comparando as frequências de emissões de todos os selos brasileiros, ano a ano (barras claras), com emissões dos selos focando o eixo-temático Engenharias (barras escuras). Percebe-se, por intermédio de uma simples conferência da figura, que é possível identificar que os primeiros selos emitidos no âmbito das Engenharias (com os temas: viação, indústria, agricultura e aviação) ocorreram a partir de 1920. A figura também mostra uma expressiva evolução na quantidade de selos desse "eixotemático central" a partir de 1950, provavelmente ocasionado pela influência do início da revolução industrial brasileira. Identifica-se uma concordância no número relativo de emissões dessas duas categorias a partir de 1970. Certamente que os apelos às questões ambientais e os progressivos avanços nas tecnologias, especialmente em telecomunicações, influenciaram essas emissões, o que refletiu nas flutuações detectadas no histograma da figura.

Considerou-se o total de selos emitidos pelo Brasil no âmbito das diferentes áreas envolvendo as Engenharias e agrupou-se por assuntos abordados em subáreas, segundo a divisão proposta pela Coordenação de Aperfeiçoamento de Pessoal de Nível Superior (CAPES) e descrita por Pedroso e Pilatti (2009). Esse procedimento revelou que nesse período o eixo-temático Engenharia Aeroespacial possui o maior número de emissões (148 selos; 23,61\% do total). 0 eixotemático Engenharia Ambiental aparece em segundo lugar nessas estatísticas, com 131 selos (20,03\%), sendo relevante o ano de 1992 devido à Conferência das Nações Unidas sobre o Meio Ambiente e Desenvolvimento (ECO-92), ocorrida no Rio de Janeiro, quando, nessa oportunidade, foram emitidas 10 diferentes estampas lembrando os diversos problemas ambientais. 


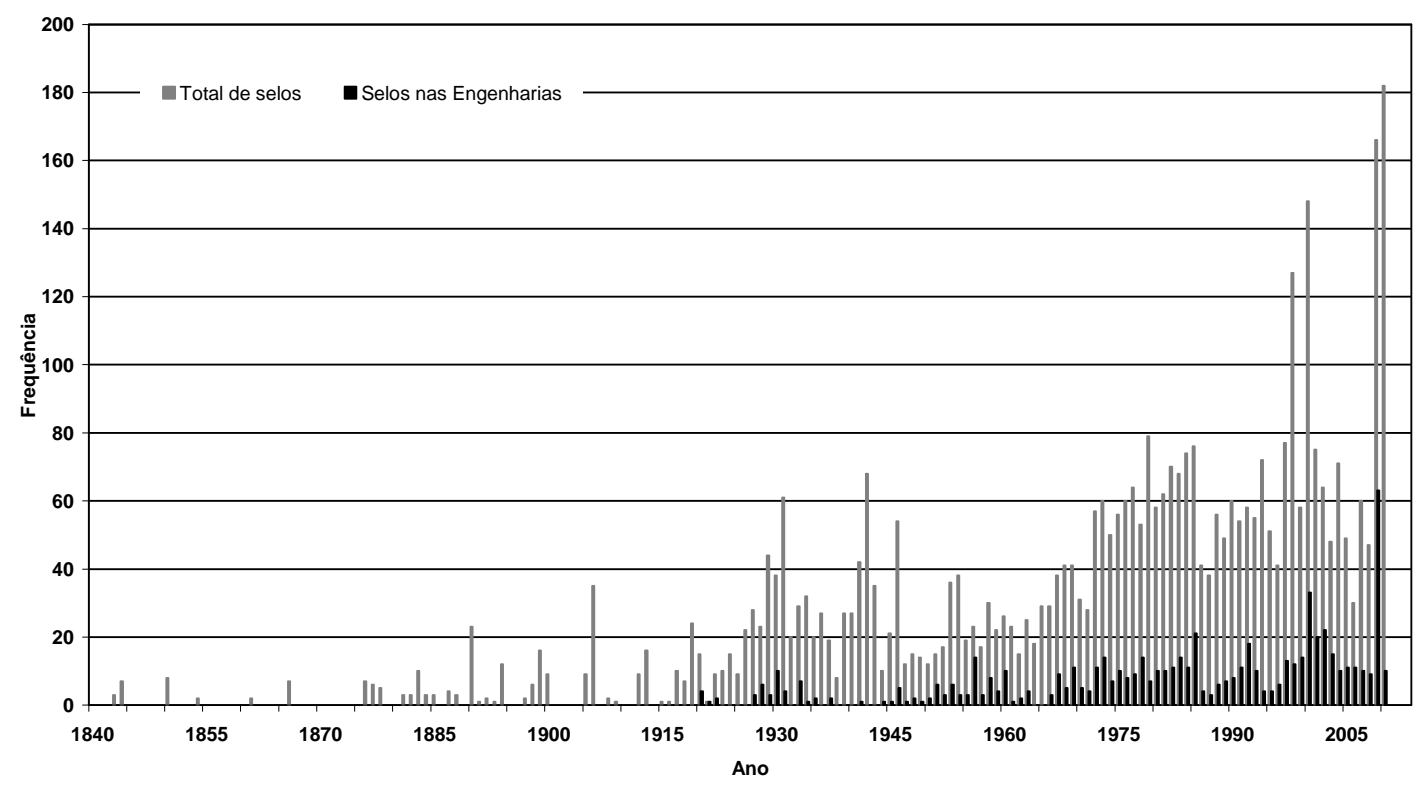

Figura 1 - Evolução dos selos postais brasileiros (1843 a 2010), comparados com os selos do eixotemático Engenharias.

O levantamento filatélico ainda encontrou 47 selos (7,19\%), relacionados ao eixo-temático Personalidades, isto é, selos que homenagearam pessoas que, de uma forma ou de outra, se envolveram com o desenvolvimento das Engenharias no Brasil. A Tabela 1 procura resumir essas estatísticas, mostrando cada subárea das Engenharias considerada nesse trabalho, assim como as quantidades e as frequências com que os selos apareceram desde o início das emissões filatélicas até a presente data.

Diante da miríade de possibilidades vislumbradas pelo eixo-temático Engenharias, a seguir são apresentados exemplos de algumas áreas das Engenharias elencadas na Tabela 1. Optou-se em mostrar esses exemplos por meio de figuras que reproduzem esses selos postais comemorativos. Essa conduta resultou num material básico para que o interessado possa se envolver com o assunto e, o mesmo tempo, sirva como um instrumento provocador para que se possa vivenciar a produção do conhecimento e a evolução sofrida pelas Engenharias, a partir de informações históricas contidas nesse material filatélico. 
Tabela 1 - Estatística realizada para os selos brasileiros com eixo-temático na diferentes áreas das Engenharias.

\begin{tabular}{|c|c|c|c|}
\hline Área & Sub-área & Quant. & Freq. (\%) \\
\hline \multirow[t]{3}{*}{ Engenharias I } & Civil & 92 & 14,07 \\
\hline & Transportes & 46 & 7,03 \\
\hline & Ambiental & 131 & 20,03 \\
\hline \multirow[t]{4}{*}{ Engenharias II } & Materiais e Metalúrgica & 11 & 1,68 \\
\hline & Minas & - & - \\
\hline & Nuclear & 2 & 0,31 \\
\hline & Química & 12 & 1,83 \\
\hline \multirow[t]{4}{*}{ Engenharias III } & Aeroespacial & 148 & 23,61 \\
\hline & Produção & 4 & 0,61 \\
\hline & Mecânica & 22 & 3,36 \\
\hline & Naval e Oceânica & 58 & 8,86 \\
\hline \multirow[t]{2}{*}{ Engenharias IV } & Biomédica & - & - \\
\hline & Elétrica & 63 & 9,63 \\
\hline Personalidades & Todas & 47 & 7,19 \\
\hline $\begin{array}{l}\text { Conotações } \\
\text { acadêmicas }\end{array}$ & Todas & 18 & 2,75 \\
\hline Total geral & & 654 & 100,00 \\
\hline
\end{tabular}

\section{Personalidades envolvidas com as Engenharias}

Algumas pessoas que dedicaram parte de suas vidas no desenvolvimento de algum ramo das Engenharias foram homenageadas e aparecem em diferentes séries filatélicas. No levantamento realizado, essa temática (Personalidades) foi representada com 47 selos dos quais se destacam 14 na Figura 2. Das estampas apresentadas nessa figura apenas as duas primeiras (Figura 2A), emitidas no ano de 1937, não aparecem com a imagem da personalidade a qual se homenageia, neste caso o engenheiro civil e prefeito do Rio de Janeiro entre 1902-06, Francisco Pereira Passos (1836-1913). A Figura 2B reproduz o selo de 1952 mostrando o engenheiro Guilherme Schüch, conhecido como Barão de Capanema. Capanema foi professor no curso de 
Engenharia da Escola Militar, realizando contribuições direcionadas à mineração e mineralogia brasileira.

O pioneiro da aviação brasileira, Alberto Santos Dumont, domina o eixo-temático Personalidades, sendo homenageado entre 1929 a 2008 com 23 estampas postais. A Figura 2C mostra uma dessas estampas, celebrando o "Centenário da Digiribilidade" ocorrido em 1999. Os selos das Figuras 2D, 2E e 2F mostram, respectivamente, o engenheiro e urbanista paraense Aarão Leal de Carvalho Reis (1853-1936), o engenheiro eletrotécnico Adel Pinto (1965- ) e o engenheiro civil André Augusto Paulo de Frontin (1860-1933). O selo em homenagem ao centenário de nascimento do engenheiro civil, deputado federal e ministro do exterior no governo Washington Luís, Octavio Mangabeira (1886-1960), aparece na Figura 2G. O físico italiano, pioneiro nas comunicações telegráficas, Guglielmo Marconi (1874-1937), foi homenageado com o selo, emitido em 1995, que aparece na Figura 2H. Também, no mesmo ano, a ECT homenageou o jornalista, engenheiro e professor no Curso de Engenharia na Escola Militar, José Maria da Silva Paranhos (1819-1880), também conhecido por Visconde de Rio Branco (Figura 2I).

O engenheiro civil e arquiteto, que veio a tornar-se prefeito da cidade de São Paulo por duas vezes (1938 a 1945 e entre 1961 a 1965), Francisco Prestes Maia (1896-1965), foi lembrado com um selo de 1996 (Figura 2J). Neste mesmo ano, a ECT decidiu emitir um selo, reproduzido na Figura $2 \mathrm{~K}$, em homenagem ao político e construtor responsável pela capital federal, Brasília, Israel Pinheiro da Silva (1896-1973). Em comemoração ao centenário da morte de Luiz de Queiroz (1898-1998), o selo em que aparece o busto desse vulto da ciência brasileira, com a fachada da Escola Superior de Agricultura que leva seu nome (ESALQ) e um ramo de um dos produtos agrícolas mais importantes do Brasil, o café, está reproduzido na Figura 2L. Por fim, o selo da Figura $2 \mathrm{M}$ homenageia o engenheiro e ex-ministro das comunicações do governo Fernando Henrique Cardoso, Sérgio Roberto Vieira da Motta (1940-1998). Muitos outros engenheiros foram homenageados pelo correio brasileiro e levados em consideração nesse levantamento, porém, por questão de espaço, foram omitidos. 


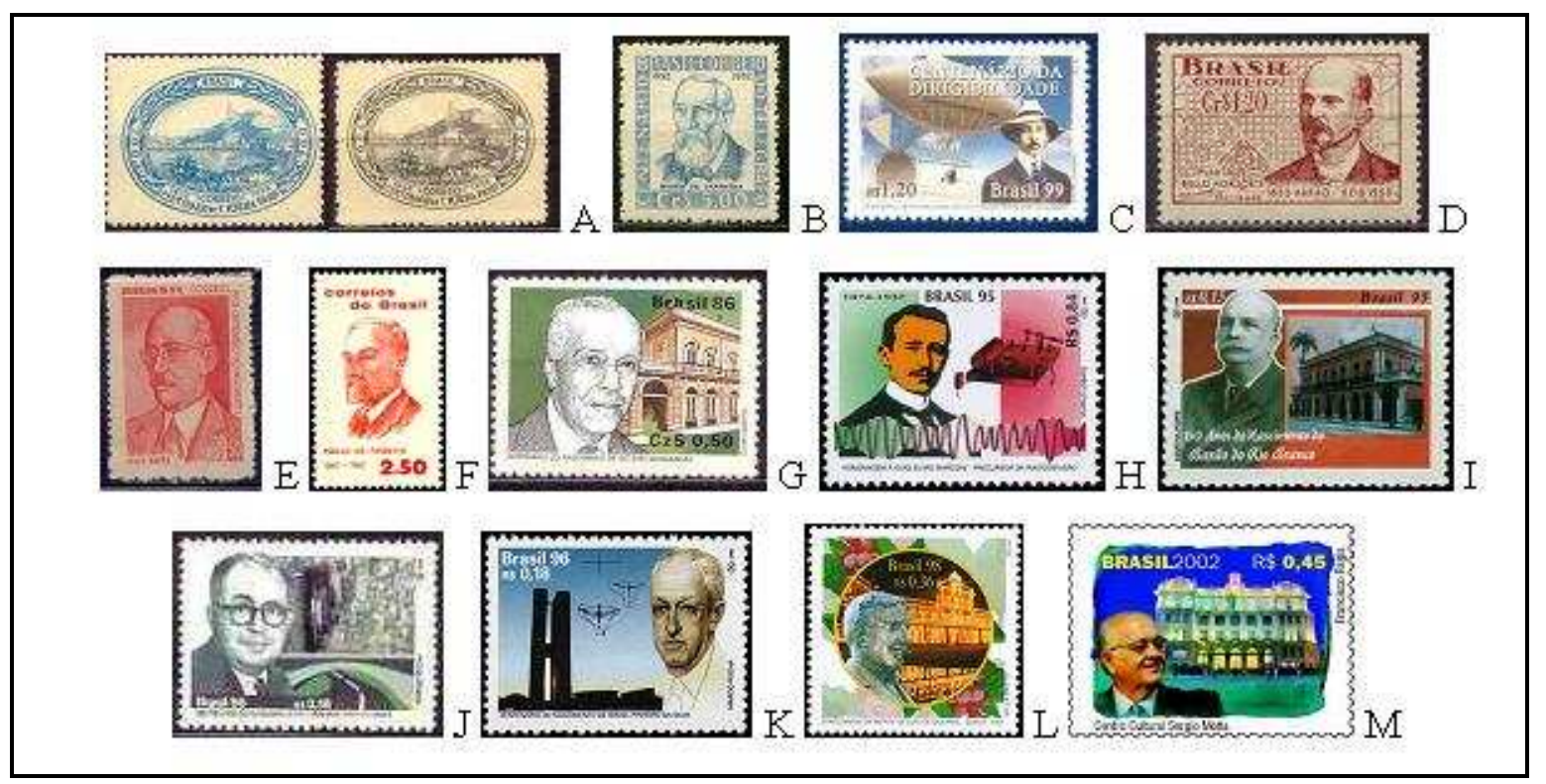

Figura 2 - Exemplo de selos postais de pessoas que se destacaram no eixo-temático Personalidades e foram homenageadas por intermédio de estampas brasileiras emitidas pela ECT.

(Fonte: Empresa Brasileira de Correios e Telégrafos)

\section{Conotações acadêmicas nas Engenharias}

As escolas técnicas, faculdades, universidades e institutos de pesquisas, assim como os encontros científicos (reuniões, congressos e simpósios), frequentemente foram lembrados e/ou homenageados em forma de selos postais. Algumas escolas de engenharias foram representadas por estampas quando da época de seus aniversários e estão representados na Figura 3. É o caso do cinquentenário (1981) do Instituto Militar de Engenharias (IME) que aparece no selo da Figura 3A. A Escola Politécnica da USP (Figura 3B), a Escola de Engenharia da UFRJ (Figura 3C) e a Escola Federal de Engenharia de Itajubá (Figuras 3D e 3E), também foram homenageadas com motivos filatélicos pela ECT. O centenário do Instituto Agronômico de Campinas (IAC), ocorrido em 1987, foi lembrado em selo emitido em 27/06/1987 (Figura 3F). Da mesma forma, o centenário (24/06/1999) do Instituto de Pesquisas Tecnológicas de São Paulo (IPT), foi referenciado com o selo que está ilustrado na Figura 2G. O II Congresso Brasileiro de Aeronáutica (Figura 3H) e o X Congresso Internacional de Estradas de Rodagem (Figura 31), ambos ocorridos no Rio de Janeiro em 13/03/1955 e 20/09/1959, respectivamente, também foram referenciados em selos postais pela ECT. A pós-graduação em Engenharias e o centenário do Clube de Engenharia, ocorrido em 22/12/1980, foram lembrados pelos selos que estão ilustrados nas respectivas Figuras $3 \mathrm{~J}$ e $3 \mathrm{~K}$. 

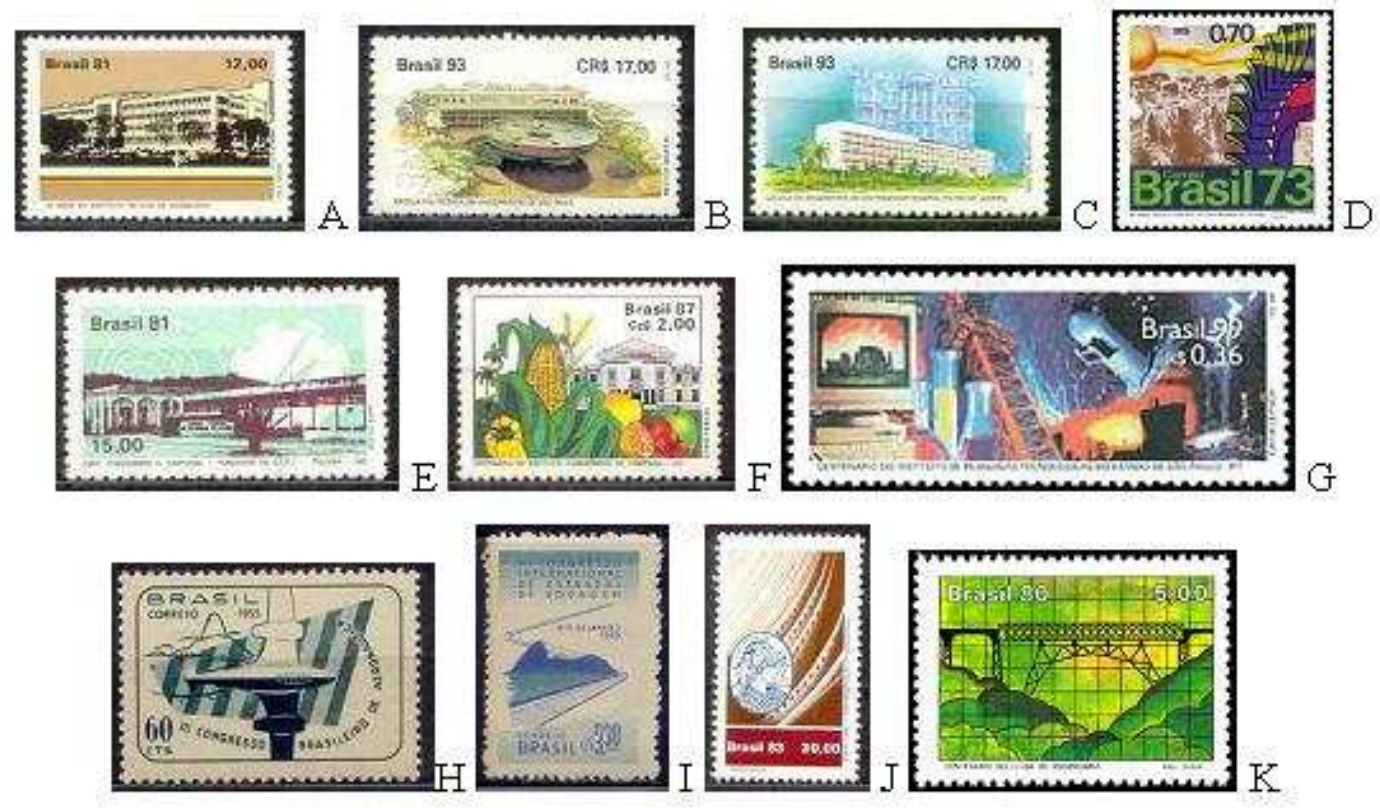

Figura 3 - Alguns selos do eixo-temático Conotações acadêmicas, que possuem alusão às escolas, clubes, congressos, simpósios relacionados às Engenharias, lançados pela ECT.

(Fonte: Empresa Brasileira de Correios e Telégrafos)

\section{Telecomunicações (Engenharias IV)}

Desde a invenção do telégrafo sem fios (1899), além do rádio transmissor, por Gugliemo Marconi, as telecomunicações não pararam de evoluir. Muitas dessas conquistas foram lembradas por meio dos selos postais brasileiros, mostrando postes telegráficos, antenas, telefones, satélites, etc. Os dois primeiros selos relacionados a esse eixo-temático Telecomunicações estão mostrados nas Figuras 4A e 4B, ambos referenciam a 2a Conferência Sulamericana de Radiocomunicações, ocorrida no Rio de Janeiro em 1937. Na sequência, a Figura 4C mostra o selo em alusão à III Conferência Interamericana de Radiocomunicações, ocorrida no Rio de Janeiro em setembro de 1945. A inauguração da Estação Rádio Transmissora em Sapucaí, Rio de Janeiro, foi lembrada no selo de 1957 (Figura 4D). A criação do Ministério das Comunicações foi celebrada com a emissão do selo emitido 20/06/1967, reproduzido na Figura $4 \mathrm{E}$, que representa uma antena parabólica apoiada por uma torre e, no segundo plano, aparece uma pomba branca alusiva à paz, anunciada por meio das comunicações. A grande antena parabólica ilustrada pelo selo da Figura 4F é em alusão à inauguração, em 1969, da Estação Terrena da Embratel (Empresa Brasileira de Telecomunicações) para comunicações por satélite. 
Em uma Homenagem aos Meios de Comunicação, a ECT lançou em 1974 uma série de três selos (Imprensa, Rádio e TV). A Figura 4G ilustra o segundo selo dessa série, mostrando uma antena e as ondas de rádio se propagando pelo espaço. O selo também é uma homenagem a Edgar Roquete Pinto (1884-1954), considerado o pai da radiodifusão no Brasil.

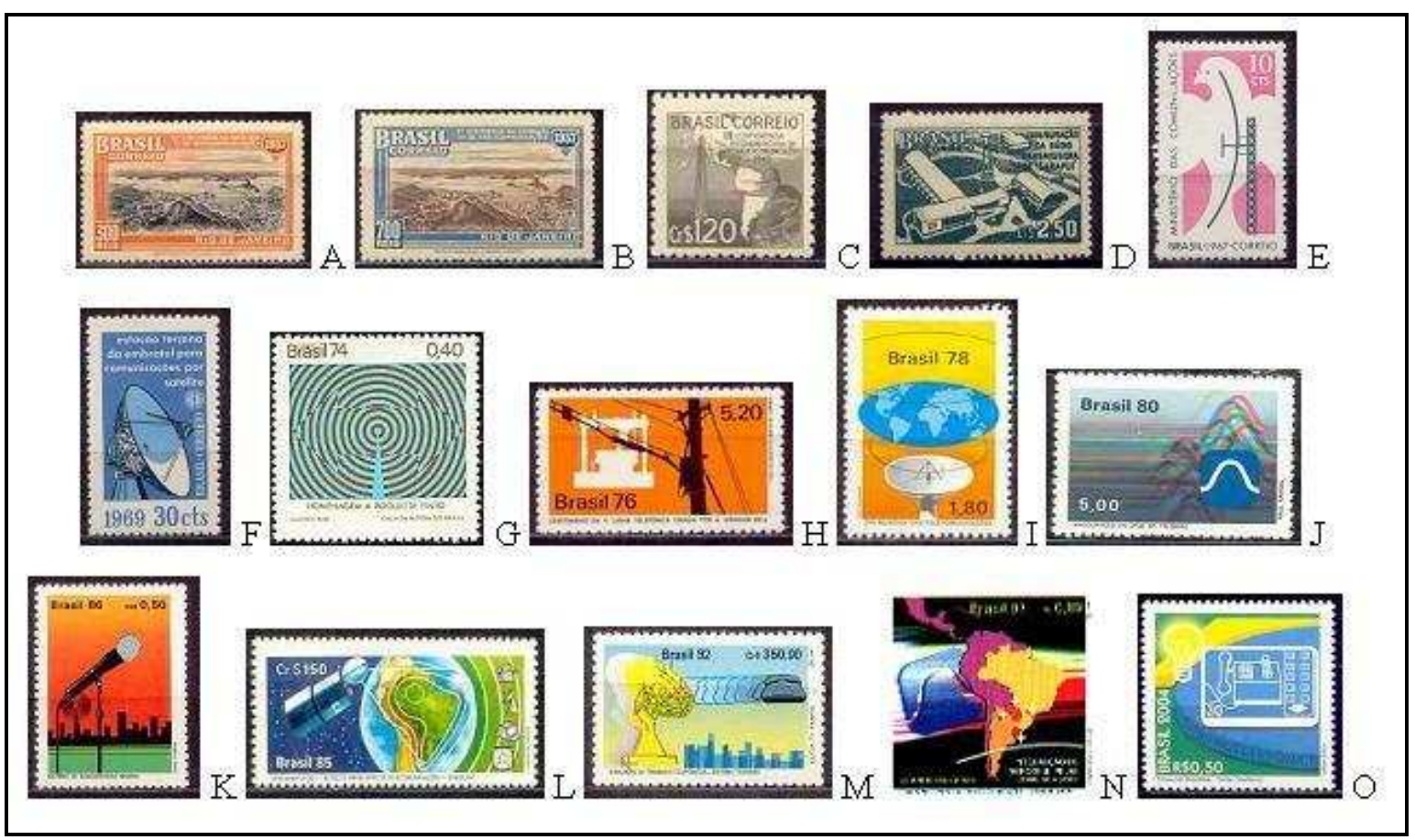

Figura 4 - Alguns selos do eixo-temático Telecomunicações lançados pela ECT.

(Fonte: Empresa Brasileira de Correios e Telégrafos)

O centenário da criação da primeira linha telefônica concebida por Alexander Graham Bell (1876) foi celebrado pela ECT em 10/03/1976, por meio de um selo mostrando um poste com as fiações nele fixadas e a silhueta de um aparelho telefônico (Figura 4H). O Dia Mundial das Telecomunicações (17/05/1978) foi retratado em um magnífico selo da Figura 4I, em que aparece uma antena parabólica emitindo sinais para o mundo (representado pelo planisfério terrestre). A inauguração do Centro de Pesquisas e Desenvolvimento (CPqD) da Telebrás (Campinas), em 1980, foi lembrada em forma de um selo que está ilustrado na Figura 4J. O Sistema de Rádio Difusão Federal foi motivo de homenagem pela ECT por intermédio da emissão, em 1986, de um selo que representa um microfone com a silhueta de uma cidade ao fundo da imagem (Figura 4K).

O lançamento do primeiro satélite brasileiro, o Brasilsat, em 1985 foi comemorado com o selo reproduzido na Figura 4L. Nesta figura aparece o satélite geoestacionário sobre o país emitindo sinais, juntamente com as figuras do telefone, microfone de rádio, televisão e antena parabólica (serviços prestados pelos dispositivos contidos no satélite). A cifra de 10 milhões de terminais telefônicos conquistados pelo sistema Telebrás foi tema do selo emitido em 1992 e R. B. E. C. T., vol 4, núm 2, mai./ago. $2011 \quad$ ISSN - 1982-873X 
ilustrado na Figura 4M. O selo possui em primeiro plano uma antena parabólica emitindo ondas e, estilizando através dessas, um telefone se deslocando pelo espaço. No horizonte aparecem os prédios de uma metrópole.

O selo da Figura 4N, em alusão à integração do MERCOSUL pelas comunicações e os 25 anos da Telebrás, emitido em 1997, contém, além do logotipo da Telebrás, o Brasil e a Argentina no mapa da América do Sul. Três outros selos lembrando as invenções brasileiras (válvula cardíaca, cartão telefônico e a "bina") foram emitidos em 2004. A Figura 40 mostra apenas um deles, o cartão telefônico com a opção para o usuário utilizar no máximo 30 chamadas.

\section{Ambiental (Engenharias I)}

Os selos presentes neste eixo-temático abordam o tema meio ambiente e a biodiversidade. A estampilha impressa em apenas duas cores mostrada na Figura $5 \mathrm{~A}$ reproduz o logotipo relativo ao Decênio Hidrológico Internacional (1965-1974), patrocinado pela UNESCO, com a colaboração de outras entidades da Organização das Nações Unidas. Na Campanha da Proteção Nacional de 1973 a ECT lançou quatro selos, um deles enfoca a proteção à natureza, ilustrada na Figura 5B. A conservação do meio ambiente foi foco do selo de 1976 (Figura 5C) que ilustra uma árvore se desfolhando e desfigurada. O selo da Figura 5D retrata a defesa do meio ambiente mostrando o Parque Nacional do Iguaçu, com destaque para as Cataratas do Iguaçu. A necessidade de maiores cuidados e proteção com o mundo, devido a diminuição da camada de ozônio, foi representada com uma mão sobre o planeta Terra no selo de 2000 (Figura 5E). Materiais recicláveis (vidro, papel, plástico e metal) para confecção de artesanatos foram temas de um bloco contendo quatro selos emitidos em 2003 (Figura 5F).

O "São Francisco", conhecido como o rio da integração nacional, juntamente com seus afluentes, foi representado no selo da Figura 5G. No entorno do mapa, por onde corta o rio, foram destacados: o pescador e seu barco, as quedas d'águas e uma usina hidroelétrica, enfatizando sua importância para as regiões sudeste e nordeste do Brasil. Água potável, devido à importância para a humanidade, foi temática do selo da Figura 5H, emitido pela ECT em 2004. Na estampa aparece uma citação em alusão ao MERCOSUL, juntamente com uma pessoa estilizada atingida por uma gota d'água, demonstrando o compromisso de proteger e preservar as reservas de água potável ainda existentes. Também numa emissão de 2004, um selo comemora o lançamento do Satélite CBERS-2 (Figura 5I). Em primeiro plano, a estampa apresenta parte do globo terrestre enfocando parte da América Central, a América do Sul e o Brasil e, no espaço, o satélite rastreando aspectos agrícolas e ambientais. Duas mãos se apertando, estilizando as 
bandeiras do Brasil e da China, lembram esse marco nas colaborações científicas e tecnológicas entre esses países.

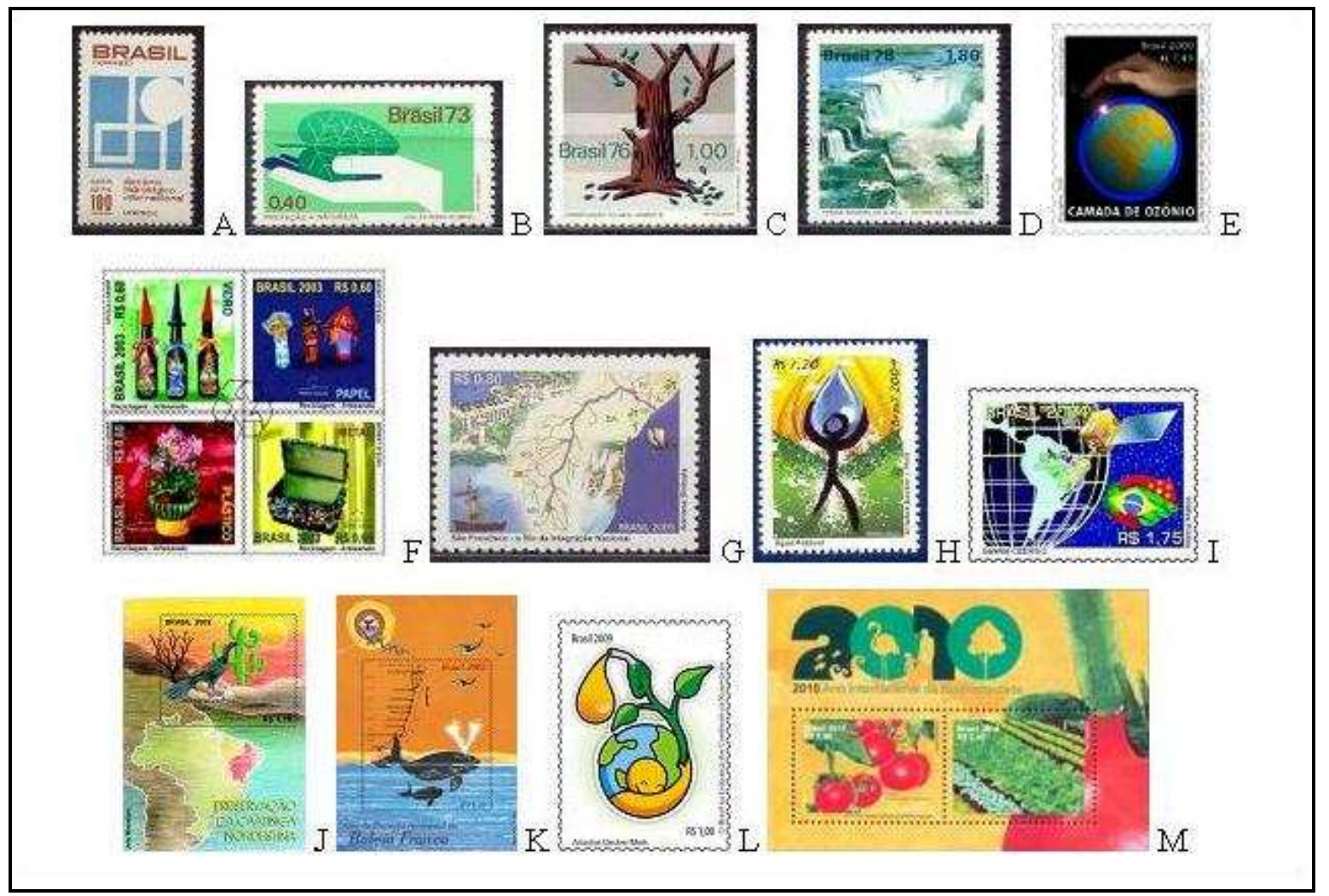

Figura 5 - Seleção de alguns selos do eixo-temático Ambiental lançados pela ECT.

(Fonte: Empresa Brasileira de Correios e Telégrafos)

No bloco filatélico emitido em 2002 (Figura 5J), foi abordada a Preservação da Caatinga Nordestina, representada pela área vermelha demarcada no mapa. Assim como no já citado selo da Figura 5B, a mão sugere responsabilidade e preocupação com a preservação deste ecossistema que, em que pese a aridez, consegue manter vivo o cacto e serve de habitat para o jacu (Penelope Jacucaca), ave que se encontra em risco de extinção devido ao desmatamento e a caça predatória. Na sequência, também no bloco de 2002, há alusão à preservação ambiental, enfocando no mapa da costa sul brasileira (região entre Florianópolis, SC e Rincão, RS) como a área de preservação da Baleia Franca (Figura 5K), a segunda espécie de baleia mais ameaçada de extinção do planeta.

O Brasil na liderança dos combustíveis renováveis foi o tema abordado pelo selo emitido em 13/01/2009 e reproduzido na Figura 5L. Para celebrar 2010 como o Ano Internacional da Biodiversidade, a ECT emitiu o bloco contendo dois selos representando a importância dos alimentos para a humanidade (Figura 5M). 


\section{Outros eixos-temáticos das Engenharias}

Como dito antes, outras subáreas das Engenharias foram cobertas no levantamento realizado neste trabalho. Infelizmente, devido à questão de espaço e aliado ao extenso material filatélico, não foi possível mostrar todos os selos envolvidos nesta pesquisa. Desta forma, optouse neste item em mostrar, por meio da Figura 6, uma pequena amostra de selos relacionados a essas subáreas como as Engenharias Civil, Naval, Nuclear, Elétrica, Mecânica, Agrícola, Siderúrgica, dentre outras. Nesses casos o leitor deve estar atento diante da grande quantidade de selos existentes nessas subáreas.

Justamente em função da extensão do material, decidiu-se subdividir as subáreas em temas mais específicos. Assim, no caso da Engenharia Civil, dividiu-se esse eixo-temático em Barragens, Edificações, Pontes, Ferrovias, Rodovias, Portos e Aeroportos. As Figuras 6A, 6B e 6C mostram três barragens hidrelétricas de importância na história das Engenharias. O selo da Figura 6A, emitido em 15/01/1955, celebra a inauguração da Usina Hidrelétrica de Paulo Afonso, localizada no Rio São Francisco. A homenagem ao centenário da primeira hidrelétrica da América do Sul, a Usina de Marmelos, em Juiz de Fora (MG), aparece no selo de 1989 e reproduzido na Figura 6B. A inauguração da maior usina em produção de energia do mundo, a Usina Hidrelétrica de Itaipu, no rio Paraná, aparece no selo emitido em 1983 (Figura 6C).

A construção da capital federal, Brasília, inaugurada no dia 20 de abril de 1960, foi lembrada por um selo de 1958, mostrado na Figura 6D, onde aparece em destaque o Palácio da Alvorada. Por outro lado, em 2007 a ECT emitiu uma série de quatro selos lembrando alguns estádios de futebol espalhados pelo Brasil, dentre esses foram homenageados os estádios: Mangueirão (Belém, PA), Serra Dourada (Goiânia, GO), Pacaembu (São Paulo, SP) e, reproduzido na Figura 6E, o estádio Maracanã (Rio de Janeiro, RJ). Muitas pontes e viadutos também foram lembrados por meio dos selos postais, é o caso da Ponte Juscelino Kubitschek em Brasília (Figura 6F) e da Ponte Estaiada em São Paulo (Figura 6G).

No âmbito das estradas e rodovias, foram identificados vários selos comemorativos. Em pleno regime militar brasileiro, uma série de selos emitidos em 1972, retrata a então denominada Campanha da Integração Nacional. É neste contexto que o selo da Figura $6 \mathrm{H}$ mostra a proposta de expandir as estradas de rodagem pela Amazônia, destacando as rodovias Transamazônica, Perimetral Norte, dentre outras. A Figura $6 \mathrm{I}$ mostra a série contendo três selos (mapa, caminho e tropeiro) em alusão a famosa "Estrada Real". 
Em relação às ferrovias, essas foram extensivamente lembradas por meio das estampas postais, sendo o primeiro selo emitido nesta temática em 1920. A Figura $6 \mathrm{~J}$ mostra o selo emitido em 05/03/1979 celebrando a inauguração do metrô da cidade do Rio de Janeiro. A inauguração da ferrovia que escoa o minério de ferro para o porto de Carajás foi homenageada com o selo da Figura 6K. Neste selo percebe-se a ênfase dada à preservação da floresta, à retirada do minério, seu escoamento por ferrovias e embarque em navios.

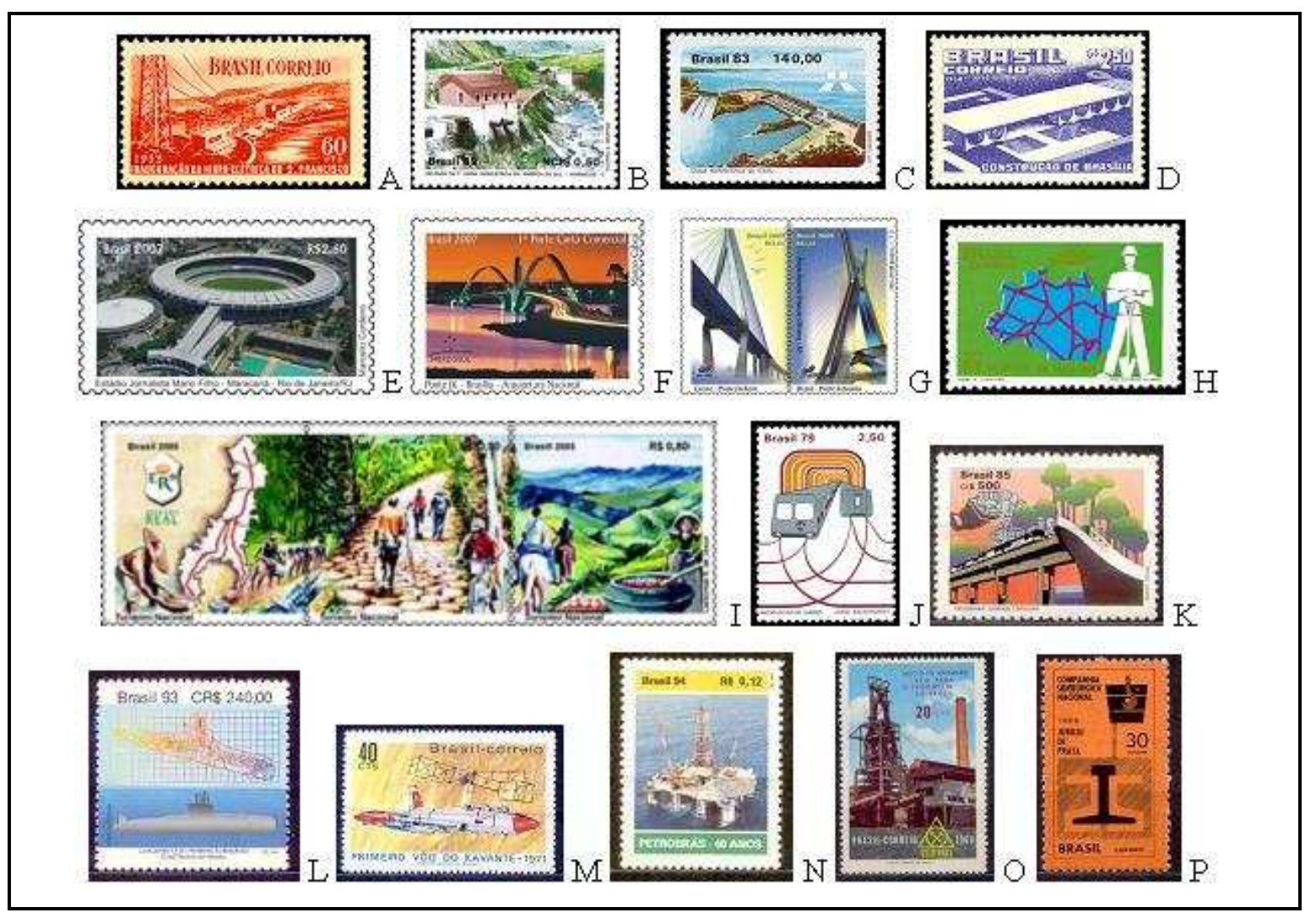

Figura 6 - Seleção de alguns selos de diferentes eixos-temáticos.

(Fonte: Empresa Brasileira de Correios e Telégrafos)

Algumas embarcações, dentre elas, barcos, navios e submarinos, também foram motivos de homenagens por meio dos selos postais. O lançamento do primeiro submarino construído no Brasil, batizado de "Tamoio", foi celebrado por meio da estampa reproduzida na Figura 6L. Assim como as embarcações, muitas aeronaves de diferentes tipos e modelos foram lembradas por meio dos selos. A Figura 6M homenageia o primeiro vôo do jato militar brasileiro, ocorrido em 1971, batizado de "Xavantes". Nesta mesma figura destaca-se o "14Bis", a aeronave mais famosa do "Pai da Aviação", Alberto Santos Dumont.

Muitas empresas relacionadas ao "eixo-temático central" Engenharias foram lembradas por meio de estampas postais. A maior empresa estatal brasileira, a PETROBRÁs, foi várias vezes 
homenageada pela ECT. O selo reproduzido na Figura $6 \mathrm{~N}$ mostra uma dessas homenagens, quando a empresa celebrou seus 40 anos de fundação. A USIMINAS, empresa de destaque na produção de aço, também foi homenageada no selo da Figura 60, em função da importância que a expansão dessa matéria-prima trazia para o país em 1969. Da mesma forma, em 1966, a ECT celebrou o Jubileu de Prata da COMPANHIA SIDERÚRGICA NACIONAL (CSN) por meio do selo da Figura 6P.

Por meio desta pequena, porém significativa amostra, é possível perceber a beleza e a riqueza que os selos postais, com o tema Engenharias, demonstram como um material didático e cultural. Observa-se que existe um farto material a ser explorado em nosso patrimônio cultural e que a utilização de selos postais, como veículo de comunicação, poderá auxiliar a diminuir a distância que separa o cidadão comum e o desejado conhecimento de nossa ciência.

\section{A situação atual e propostas de ação}

O hábito de colecionar selos pelo mundo a fora vêm sofrendo algumas consequências devido à disseminação da Internet, assim como pela mídia eletrônica e digital, provocando um aumento de oferta e demanda de selos para os colecionadores, devido à facilidade de aquisição desses materiais (Carazo, 2001). Obviamente que no Brasil a situação não é diferente, mas é possível encontrar colecionadores em várias localidades do território nacional interessados por temas relevantes da nossa cultura popular, história, geografia, riquezas naturais e da ciência. Coleções temáticas abordando assuntos como transportes, igrejas, monumentos arquitetônicos, políticos, músicos, flora, fauna, parques nacionais, dentre outros, reforçam ainda mais a importância da filatelia brasileira.

Apesar de ser um tema timidamente explorado por filatelistas espalhados pelo mundo, a temática Engenharias, explorada por meio dos selos postais, não passou despercebida pela ECT e, tão pouco, por alguns filatelistas nacionais. Certamente, nos países da Comunidade Européia e nos Estados Unidos encontra-se uma maior tradição e cuidado na apresentação de muitos temas filatélicos, incluindo o eixo-temático destacado neste trabalho. A título da importância que esses povos dão à filatelia, destacam-se os livros: "Um Certo Olhar pela Filatelia", do português Luis Eugénio Ferreira (Ferreira, 2006), e "European Stamp Design: a semiotic approach to designing messages", do irlandês David Scott (SCOTT, 1995). No primeiro, o autor ressalta a importância dos selos por meio de aspectos da política e história dos povos europeus. O segundo aborda de forma pioneira o selo postal sob uma perspectiva da semiótica. O livro contém elementos icônicos e simbólicos sob o olhar dos selos postais, explorando o design filatélico de cinco países (França, Holanda, Inglaterra, Irlanda e Suíça). Numa passagem da referida obra, Scott dimensiona a 
importância do selo nas seguintes palavras "... o selo postal adesivo possui uma densidade de concentração ideológica por polegada quadrada maior do que qualquer outra forma de cultura humana" (Scott, 1995, p. 73).

É importante ressaltar que para um colecionador, uma simples paisagem exibindo uma ponte, uma rodovia, uma torre de transmissão, ou uma barragem, pode ser explorada de algum ponto de vista da Engenharia. Entretanto, é necessário diferenciar os selos nos quais o motivo temático apenas faz parte da "paisagem de fundo" daqueles em que esse tema é o principal motivo estampado. Justamente, nesse último grupo são encontrados alguns dos selos mais belos de divulgação e úteis para o uso dos professores com seus estudantes em atividades acadêmicas. Neste contexto, os selos postais podem servir como mais uma opção para o ensino e para a aprendizagem, pois esse material é um recurso atraente podendo fazer uso de dispositivos auxiliares como retroprojetores, datashow, fotografias, internet, etc.

Com certeza, a abordagem educativa ainda é um desafio para muitos educadores, indicando que há um longo caminho a ser percorrido. Mas, vale ressaltar que, a aprendizagem das engenharias (e de outros conteúdos científicos) pode acontecer em âmbitos diversificados, como no caso da educação formal, informal, ou ainda nas atividades denominadas de popularização da ciência. Assim, quanto mais ampla a divulgação, a disseminação e a difusão dos conteúdos existentes nos selos postais, mais facilmente e com maior eficiência ocorrerá a transposição didática de saberes científicos.

Desde que tais espaços não formais, como os que foram aqui propostos por meio do uso dos selos postais, sejam utilizados com a finalidade de participar dos processos de ensino e aprendizagem de forma planejada, sistemática e articulada, o material filatélico empregado deixa de se tornar uma mera atividade educacional de complementação ou de lazer, passando a contribuir para a educação e o aprendizado de conteúdo geral ou, em certas aplicações, específico de um curso de engenharia.

\section{Considerações finais e perspectivas}

Este trabalho consiste numa tentativa de contribuir com um campo relativamente inexplorado da literatura científica nas áreas das Ciências Exatas: a interseção entre as Engenharias e a Filatelia. A partir dos selos brasileiros buscou-se resgatar uma importante função para as diferentes áreas das engenharias, a comunicação de informações espaciais empregada na codificação de signos existente nesse tipo de material, que carrega diferentes significados culturais.

Por meio do levantamento realizado, ficou evidente que a filatélica brasileira, envolvendo a temática Engenharias, é caracterizada pela emissão de selos que representam elementos da História de Personalidades da Engenharia, do Desenvolvimento da Engenharia Brasileira, da 
Engenharia Temática e da inter-relação entre as Engenharias e outras ciências. Teoricamente, é possível verificar por meio das estampas postais os valores ligados às comunicações e transportes, histórias, técnicas em construção, as fontes diversificadas de energias, os vários temas ambientais, dentre outros.

Os selos postais agrupados e ilustrados neste trabalho por eixos-temáticos abordam, basicamente, algumas personalidades e entidades e/ou instituições relacionadas às engenharias, além da engenharia temática nos eixos: telecomunicações, ambientes (destacando as energias renováveis e não renováveis), transportes, edificações e tecnologias.

No levantamento efetuado, constatou-se que o eixo-temático Ambiental caracteriza-se fundamentalmente pela preocupação em relação às campanhas de conscientização sobre desenvolvimento sustentável, prevenção e preservação do meio ambiente. Percebeu-se ainda que, os selos postais de outros eixos-temáticos, como Transportes, utilizam como elementos contendo escalas variadas a representação de diferentes mapas e de rotas rodoviárias, além de focar as ferrovias, embarcações e aeronaves. No caso do eixo-temático Telecomunicações, os selos se notabilizam pela evolução marcante das tecnologias envolvidas nas emissões de sinais de rádio e televisão, além das comunicações via satélite. Todos esses materiais filatélicos representam os fluxos de grande quantidade de informações, pessoas, mercadorias e capitais, fatores fundamentais para o desenvolvimento de uma nação.

Uma temática que deveria ser mais bem explorada é a das Personalidades que contribuíram decididamente para o desenvolvimento de alguma das áreas das Engenharias. Este eixo-temático é o reflexo da importância do desenvolvimento da ciência em nosso país. Sendo assim, ocorrem as interfaces entre os vários eixos-temáticos no que diz respeito a aspectos da História da Engenharia.

Assim como a cultura é elemento central, mediador das relações entre sociedade e natureza, os processos de comunicação são fundamentais à produção e reprodução cultural. 0 profissional que utiliza a informação como objeto de trabalho e estudo pode assumir uma postura ativa e como consequência o de agente transformador e mediador crítico da sociedade, gerando uma cultura dinâmica e interativa. Dentre as diversas mídias disponíveis, os selos postais representam, indubitavelmente, um poderoso veículo de comunicação, veículo este ainda pouco explorado no âmbito das Engenharias. Isso pode favorecer uma formação mais geral do engenheiro e dessa forma facilitar o exercício pleno de suas funções na sociedade. É preciso buscar uma formação de engenheiros, que além de forte embasamento específico, possua cultura humanista e sensibilidade para os problemas sociais e ambientais. A iniciativa e os resultados obtidos neste trabalho revelam uma miríade de possibilidades de estudo dos conteúdos dos selos 
postais brasileiros, sobretudo aqueles relacionados a temas clássicos da Engenharia. Seria interessante que trabalhos futuros explorassem esse gigantesco manancial.

\section{Referências}

Brasil, Resolução CNE/CES 11/2002. Diário Oficial da União, Brasília, 09 de abril de 2002. Disponível em: <http://portal.mec.gov.br/cne/arquivos/pdf/CES112002.pdf>. Acesso em: 16/fev/2011.

Carazo, J. E. A. Filatelia: coleccionismo, comercio e inversión. Boletin Económico de Información Comercial Española. v. 2713, p. 41-47, 2001.

Castro, J. F. M.; Diniz, A. M. A.; Barros, G. F. Interseções Geográficas: uma análise da cartografia filatélica brasileira. Sociedade \& Natureza. v. 19, n. 2, p. 153-169, 2007.

Chodirker, B. N.; Chudley, A. E. Genetic landmarks through philately - epilepsy and clinical genetic issues. Clinical Genetics. v. 66, p. 290-292, 2004.

Chudley, A. E. Genetic landmarks through philately - symbols in medicine. Clinical Genetics. v. 54, p. 474-476, 1998a. . Genetic landmarks through philately - Gregor Johann Mendel (1822-1884). Clinical Genetics. v. 54, p. 121-123, 1998 b. . History of genetic through philately - Carl Linnaeus (Carl von Linné). Clinical Genetics. v. 60 , p. $104-106,2001$ a. . Genetic landmarks through philately - Charles Robert Darwin. Clinical Genetics. v. 60, p. 270-272, 2001b. ; Chodirker, B. N. Landmarks in genetics through philately: Down syndrome. Clinical Genetics. v. 63, p. 268-272, 2003.

Costa Neto, E. M. Entomofilatelia: os insetos na arte filatélica. Bioikos. v. 16, n. 1-2, p. 61-67, 2002.

Empresa Brasileira de Correios e Telégrafos (ECT). Informe Publicitário: Filatelia. São Paulo: Contadino. 2002a.

Empresa Brasileira de Correios e Telégrafos (ECT). 2010. Histórico do selo. Disponível em: <http://www.correios.com.br/selos/historico.cfm>. Acesso em: 16/set/2010.

Ferreira, L. E. Um Certo Olhar pela Filatelia. Santarém (Portugal): Edições Húmus. 2006. Fonseca, M. L. T. A. Selos postais: fonte de inovação, arte e beleza promovendo a comunicação. Correio Filatélico. v. 210, p. 24-25, 2008. 
Gómez Y Gómez, B.; Junghans, C. Los Scarabaeoidea (Insecta: Coleoptera) en la filatelia.

Cuadernos de Biodiversidad. v. 11, p. 10-14, 2002.

Martínez, J. G.; Peregrín, J. M. S. La Química a través de sus sellos: uma revisión comparativa de la filatelia dedicada a Mendeléiev. Anales de la Real Sociedad Española de Química. v. 103, n. 1, p. 50-57, 2007.

Meyer, R. H. O Catálogo de Selos do Brasil 2010. São Paulo: Editora RHM Ltda. 2010.

Micotti, M. C. O. O ensino e as propostas pedagógicas. In: Bicudo, M. A. V. (org). Pesquisa em Educação Matemática: Concepções e Perspectivas. São Paulo: Editora Unesp. 1999, p. 153-168.

Morgan, M. A. A Postage Stamp History of the Atom, Part II: the quantum era. Philatelia Chimica et Physica. v. 28, n. 1, p. 35-43, 2006.

Pedroso, B.; Pilatti, L. A. O Novo Qualis: pesrspectivas para a pós-graduação em engenharia de produção. Revista Gestão Industrial. v. 05, n. 02, p. 44-60, 2009.

Penereiro, J. C. A filatelia como forma de divulgação da astronomia. Caderno Catarinense de Ensino de Física. v. 14, n. 1, p. 64-82, 1997.

Ramírez, M. M.; Rueda, I. P.; Cordero, M. A. S.; García, M. L. Z. Entomofilatelia en México: un tributo a la amistad de los insectos. Boletín Sociedad Entomológica Aragonesa. v. 38, p. 443-449, 2006.

Scott, D. European Stamp Design: a semiotic approach to designing messages. Londres: Academy Editions, 1995.

Thiéblot, M. J. $O$ maravilhoso mundo dos selos. Leitura 13 (148). 1994. p. 3-6.

Webb, R. Physics: philately Will get you everyehere. Nature. v. 438, p. 1089, 2005.

Welker, C. A. D. A filatelia como forma de divulgação da flora brasileira. Revista Brasileira de Biociências. v. 08, n. 03, p. 273-278, 2010.

Júlio César Penereiro. Professor titular de Física do Centro de Ciências Exatas, Ambientais e de Tecnologias da PUC-Campinas. Doutor em Astrofísica pelo Instituto de Astronomia, Geofísica e Ciências Atmosféricas da Universidade de São Paulo (IAG-USP). jcp@puc-campinas.edu.br

Denise Helena Lombardo Ferreira. Professora titular de Matemática do Centro de Ciências Exatas, Ambientais e de Tecnologias da PUC-Campinas. Doutora em Educação Matemática pelo Instituto de Geociências e Ciências Exatas (IGCE) da Universidade Estadual Paulista "Júlio de Mesquita Filho" (UNESP). lombardo@puc-campinas.edu.br 